\title{
Contamination of Bacteria and Associated Factors among Food Handlers Working in the Student Cafeterias of Jimma University Main Campus, Jimma, South West Ethiopia
}

\author{
Tsegaye Assefa ${ }^{1}$, Haymanot Tasew ${ }^{1}$, Beyene Wondafrash ${ }^{2}$ and Jemal Beker ${ }^{{ }^{*}}$ \\ ${ }^{1}$ Department of Medical Laboratory Sciences and Pathology College of Public Health and Medical Sciences, Jimma University, Ethiopia \\ ${ }^{2}$ Department of Nursing, College of Public Health and Medical Sciences, Jimma University, Ethiopia \\ "Corresponding author: Beker J, Department of Nursing, College of Public Health and Medical Sciences, Jimma University, Ethiopia, Tel: +251932409399; E-mail: \\ jemalbeker@yahoo.com
}

Rec date: Dec 19, 2014; Acc date: Feb 19, 2015; Pub date: Feb 23, 2015

Copyright: ( 2015: Assefa T, et al. This is an open-access article distributed under the terms of the Creative Commons Attribution License, which permits unrestricted use, distribution and reproduction in any medium, provided the original author and source are credited.

\begin{abstract}
Background: Food borne diseases continue to be a major global health problem and are the leading causes of morbidity and mortality in developing countries. Food handlers play a major role in the transmission of food borne pathogens via hands. This study aimed to assess the bacterial hand contamination and associated factors among food handlers working in the student cafeterias of Jimma University main campus.
\end{abstract}

Methods and materials: A cross-sectional study was conducted from May 2012 to April 2013 among food handlers working in the student cafeterias of Jimma University main campus. The data was collected by using structured questionnaire and observational checklist. Hand rinse samples was collected from participants and microbiologically examined for the presence of potential food borne bacterial contaminants using standard laboratory methods. The data was entered into a computer and analyzed using SPSS version-16.0 software.

Result: Among 230 food handlers, 114(49.6\%) were tested positive for one or more potential food borne bacterial contaminants, and $73(31.7 \%$ ) were tested positive for enteric pathogens. A total of 171 bacterial hand contaminants were isolated. S. aureus $54(23.5 \%)$, Klebsiella spp. 37(16.1\%), E. coli $25(10.9 \%)$, Enterobacter spp. 21(9.1\%), Citrobacter spp. 10(4.3\%), Serratia marcescens 6 (2.6\%), Pseudomonas aeruginosa 8(3.5\%), Proteus spp. 5(2.2\%), Providencia rettegri $3(1.3 \%)$, and salmonella spp. $2(0.9 \%)$ were isolated with their corresponding prevalence rate. Bacterial hand contamination rate have significant association with service years (Chi-square $=13.732, D F=4$, $P=0.008)$, age $\left(X^{2}=11.308, P=0.010\right)$ and cleanness of outer garments $\left(X^{2}=7.653, P=0.006\right)$.

Conclusion: The findings of this study emphasized the importance of food handlers' hands as a potential vector for potential food borne bacterial contaminants which could constitute a potential risk to food borne outbreaks. New employees and young and inexperienced food handlers should be well trained on personal hygienic practices pointing out on the importance of hand hygiene and appropriate hand washing techniques.

Keywords: Food handlers; Food borne bacterial contaminants; Isolation rate; Hand rinse

\section{Introduction}

Foodborne diseases can be defined as diseases commonly transmitted through food. Foodborne diseases comprise a broad group of illnesses caused by microbial pathogens, parasites, chemical contaminants and bio toxins. The burden of disease can be defined as the incidence and prevalence of morbidity, disability, and mortality associated with acute and chronic manifestations of diseases [1-3]. The Centers for Disease Control and Prevention has identified more than 400 food-related illnesses. About two thirds of all outbreaks involve bacteria. The illnesses are caused either by the microorganisms themselves or by the toxins they release [4]. The consumption of foods contaminated by foodborne pathogenic microorganisms and toxins produced by them cause's deaths, illnesses, hospitalization, and economic losses. Due to their widespread nature, foodborne diseases, in particular gastro-intestinal infections, represent a very large group of pathologies with a strong negative impact on public health [5].
Many food-borne disease incidents are reported every year in Africa. Numerous factors, contribute to this high number of incidents [6-9]. However, it is extremely important to note that most cases of food-borne disease in the region are not reported, so the true extent of the problem is unknown. In most countries of the region, the surveillance infrastructure for food-borne diseases of both microbiological and chemical etiology is weak or non-existent. This absence of reliable data on the burden of food-borne disease impedes understanding about its public health importance and prevents the development of risk based solutions to its management [2].

More aggravated situations and challenges prevail in Ethiopia where food safety issues are not well understood and have received little attention. In Ethiopia, according to the Ministry of Health annual report of 2011, dysentery and gastroenteritis were among the top ten diseases of outpatient visits although the report did not include all regions activity [10]. Food-borne diseases represent a persistent global health burden, and food handlers play a major role in their transmission [11]. Even though the sources of food contamination are diverse, food handlers serve as important source of food 
Citation: $\quad$ Assefa T, Tasew H, Wondafrash B, Beker J (2015) Contamination of Bacteria and Associated Factors among Food Handlers Working in the Student Cafeterias of Jimma University Main Campus, Jimma, South West Ethiopia. Altern Integr Med 4: 185.

Page 2 of 8

contamination either as carriers of pathogens or through poor hygienic practices [12]. The mishandling of food and the disregard of hygienic measures enable pathogens to come into contact with food and, in some cases, to survive and multiply in sufficient numbers to cause illness in consumers. Personal hygiene and environmental sanitation are among the key factors in the transmission of food borne diseases [13].

Several food-borne disease outbreaks are associated with poor personal hygiene of people handling foodstuffs. CDC reported that approximately $20 \%$ of food-related infections are due to food handlers [14]. Another study conducted in Malaysia also showed that approximately $10-20 \%$ of food-borne disease outbreaks are due to contamination by the food handlers [13]. Food workers may transmit pathogens to food coming from a contaminated surface of another food, or from hands contaminated with organisms from their gastrointestinal tract. This is also supported by report in which about $89 \%$ of outbreaks caused by food contamination by food workers, pathogens were transferred to food by workers' hands by Michaels et al. [15].

Food handlers are the most important sources for the transfer of microbial pathogens to food either from their hair, skin, hand, digestive systems, respiratory tracts, or from contaminated food prepared and served by them $[16,17]$. The hands are the last line of defence against exposure to pathogens which can occur either directly from the hand to the mouth, eye, nose, or other area of the skin, or indirectly by "handling" of food or water. The hands are particularly important since they are the last line of defence in the chain of transmission of gastrointestinal pathogens, either directly from handto-mouth, or indirectly by "handling" of food or water [18]. The hands of food handlers can be the vector to spread harmful microorganism through cross contamination, and during or after they experience gastrointestinal infection. An employee might contaminate his hands when using toilet, or bacteria might be spread from raw foods, from contaminated equipment, and environment [19]. Thus, these contaminated hands can transfer intestinal microbes to foods, equipment, and other workers in the food storage and preparation areas unless correct personal hygiene and adequate hand washing procedures are followed $[20,21]$. Some of the bacteria that can colonize the hands of food handlers are Escherichia coli and Staphylococcus aureus [22].

WHO emphasizes that "outbreaks of food-borne diseases can be reduced if both professional and domestic food-handlers understand the importance of correct hygienic food practices [12]. Food handlers should not smoke, sneeze, spit, cough, eat, handle money or engage in any act that could contaminate the food during the performance of their activities [23]. The role of the hands in disease transmission and the importance of hand hygiene in controlling infection in the food establishment are well established. Hand washing has been identified as the single most important means of preventing the spread of infection and if poorly or improperly implemented, can lead to foodborne illness outbreaks [23,24]. Food handlers in bigger eating establishments cater to a larger number of people, they are epidemiologically more important than domestic food handlers in spreading of food borne disease [11]. Nonetheless, bacterial hand contamination of food-handlers, may pose a real threat to those who are more susceptible to infection. Studying the hands microbial flora among the food handlers could have paramount importance to understand the hygienic practices of food handlers. The presence or absence of bacteria in the hands of food handlers can be used as a quantitative indicator of their behavior regarding food-related and personal hygiene $[25,26]$. There are few related studies in Ethiopia and specifically to this study area. Therefore, this study aimed at assessing the bacterial hand contamination among food handlers working in the student cafeterias of JU main campus.

\section{Materials and Methods}

\section{Study area and period}

The study was conducted at student cafeterias in Jimma University main campus, Jimma town, located at $355 \mathrm{~km}$ southwest Ethiopia from May 2012 to April 2013. Its geographical coordinates are: 07039' Latitude and 36050' Longitude, at an altitude of 1700-1750 m above sea level. Jimma University is organized into six colleges, out of which four of them are located in the Jimma University main campus. Around 500 food handlers are currently working in the student cafeterias of Jimma University main campus.

\section{Study design}

Descriptive cross-sectional study design was used

\section{Source population}

All food handlers working in the student cafeterias of Jimma University main campus

\section{Study population}

Selected food handlers working in the student cafeterias of Jimma University main campus

\section{Inclusion criteria}

Food handlers who are engaged in food preparation, serving, and Cleaning

\section{Exclusion criteria}

Food handlers who have skin irritation, eczema, and inflammation

\section{Sample size determination}

Sample size (n) was determined using a formula to estimate single population proportion. Taking $50 \%$ prevalence of bacterial hand contamination $(\mathrm{p}=0.5), 95 \%$

$$
n=\frac{(z \propto / 2)^{2_{\star}} P(1-P)}{d^{2}}=\frac{(1.96)^{2_{\star}}(0.5)^{2}}{(0.05)^{2}} \approx 384,
$$

where:

\section{P- Bacterial hand contamination rate}

$\mathrm{z}-\mathrm{z}$-statistics value that corresponds to 97.5 percentile cut-off point in the standard normal distribution

\section{d - Margin of error}

Since the total number of the source population was 500 , correction formula was used to adjust the sample size to the population size and the sample size was calculated further as 
Citation: $\quad$ Assefa T, Tasew H, Wondafrash B, Beker J (2015) Contamination of Bacteria and Associated Factors among Food Handlers Working in the Student Cafeterias of Jimma University Main Campus, Jimma, South West Ethiopia. Altern Integr Med 4: 185.

Page 3 of 8

$\frac{n}{1+\frac{n}{N}}=\frac{384}{1+\frac{384}{500}} \approx 218$

Finally by considering a $10 \%$ (22 subjects) non response rate, the final sample size was determined as:

$\mathrm{N}+22 \approx 240$

\section{Sampling technique}

Simple random sampling technique was employed. Study participants were selected by lottery method from the roster lists of food handlers which was obtained from students' cafeteria offices of Jimma University main campus.

\section{Variables of the study}

Dependent variables

Bacterial hand contamination

Types of bacterial hand contaminants

Independent variables

- Sociodemographic factors

- Hand washing habit

- Fingernail status

- Presence of jewelers on fingers

- Regular medical checkup

- Hygiene training

- Outer protective coat, and Hair cover

- Cleanness of outer garments

\section{Data and specimen collection}

Data related to socio-demographic characteristics, and personal hygiene practices of food handlers was collected by face to face interview method using structured questionnaire, and observational checklist. The tool was first prepared in English and then translated into the national language. Three sanitarians and two medical laboratory professionals were recruited for data collection and microbiological analysis. The data collectors were trained for two days by the principal investigator on data, and specimen collection procedures. After interviewing participants were asked to give hand rinse samples in sterile plastic bag (Stomacher@400 Classic; Seward, Worthing, UK) for microbiological analysis.

Before starting any meal preparation activity including hand washing (if any), participant's hands were sampled for microbial testing. Notification was not given in advance, and extra hand hygiene was not allowed during the hand rinse sample collection. A sterile polyethylene plastic bag technique was employed to collect the hand rinse samples. Participants were asked to dip their hands into sterile polyethylene plastic bag containing 100 milliliter of buffered peptone water (0.1\% BPW) (Difco/Becton Dickinson, Franklin Lakes, and NJ). The bag was grasped tightly around the participant's wrist and the Peptone buffer was massaged through the wall of the bag by the investigator for one 1 minute, over all surfaces of the participant's hand, particularly around the nails and palm. The bag was immediately sealed and transported to Jimma University medical microbiology laboratory for examination $[27,28]$.

\section{Isolation and identification of potential food borne bacterial pathogens}

All media used in this study were from Oxoid Ltd. and were prepared according to the manufacturer's instructions. The hand rinse samples were vortexed for one minute prior to microbiological examination. A loop full of each sample was separately spread-plated onto MacConkey (for detection of enteric bacteria), MSA (for detection of staphylococci), and XLD (for detection of Salmonella, and Shigella). Rappaport vassiliadis (RV) was used as a primary enrichment for the identification of Salmonella and Shigella. The bacterial colonies grown on the agar media were presumptively identified by colonial morphology and gram staining and a battery of biochemical tests like reaction on oxidase, catalase, simmon citrate, indole production, urease, motility, coagulase, methyl red-voges proskaeur (MR-VP), LDC, KIA, gas and Hydrogen Sulfide (H2S) production [29,30] (Figure 1).

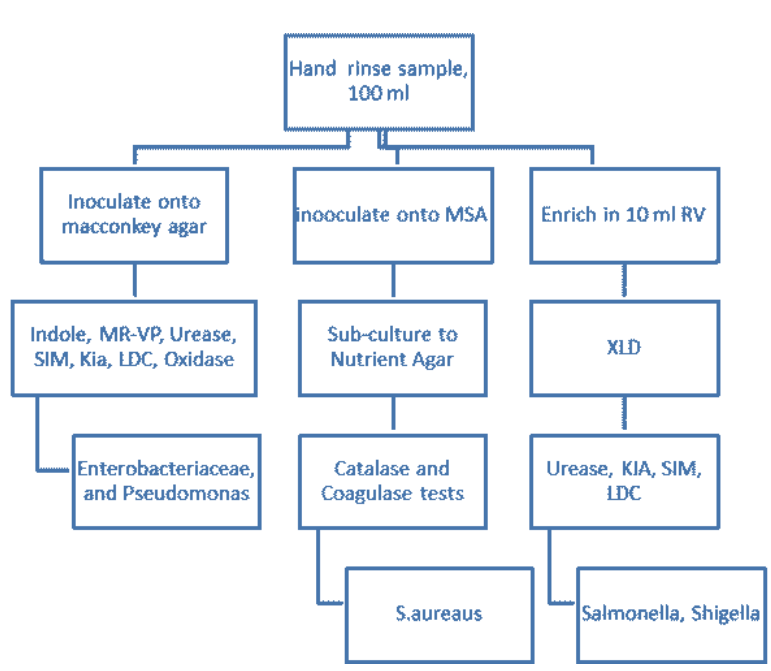

Figure 1: Simplified laboratory flow chart for identification of potential food borne bacterial hand contaminants.

\section{Quality control}

To manage the quality of the work SOP was strictly followed during processing of each sample. All the instruments used for sample processing were checked for proper functioning as far quality control strains of $S$. aureus (ATCC 6538) and E. coli (ATCC 25922) were used. Data consistency and completeness were made all the way during data collection, data entry and analysis. Culture Medias were prepared based on the manufactures instruction. Then the sterility of culture media was checked by incubating $5 \%$ of the batch at $35-37 \mathrm{oc}$ overnight and observed for bacterial growth. Those Media which shows growth was discarded.

\section{Data processing and analysis}

All components of data were entered and cleaned, coded and analyzed using SPSS version 16.0 (Copyright (c) SPSS Inc., 1997-2007, Polar Engineering and Consulting.) computer software. Data was organized, summarized, and presented in simple descriptive Statistical methods. Chi-square test was used for checking any possible association between various categorical variables, and $p$-value $<0.05$ 
Citation: $\quad$ Assefa T, Tasew H, Wondafrash B, Beker J (2015) Contamination of Bacteria and Associated Factors among Food Handlers Working in the Student Cafeterias of Jimma University Main Campus, Jimma, South West Ethiopia. Altern Integr Med 4: 185.

Page 4 of 8

considered as significant. The findings of the study were compared to other studies.

\section{Ethical Consideration}

The study was conducted after obtaining ethical clearance from Jimma University College of public health and Medical Sciences Ethical review Board. Permission letter was obtained from Jimma University Students' Service Dean Office to students' cafeteria office. Informed consent was obtained from participants after explanation of the purpose of the study and procedure of sample collection. In addition, participation in the study was made by willingness of study participants. All personal information about the study participants were kept confidential.

\section{Dissemination of the findings}

The finding of the study was disseminated to college of medical sciences and public health, Jimma University as a requirement for partial fulfillment of graduate study. The copy of the thesis results was provided to Student Cafeteria Offices of JU main campus. Furthermore a copy of the study will be submitted to health science library and Department of Medical Laboratory Sciences and Pathology. Finally, study results will be sent to the respective scientific journals requesting for publication.

\section{Operational definition}

Bacterial hand contamination: presence of one or more potential food borne bacterial hand contaminants

Food borne diseases - intoxication, infection, or illness contracted by the consumption of contaminated food

Food handler - a person who is engaged in the process of food preparing, serving, cleaning, and etc.

Potential food borne bacterial contaminants - bacterial pathogens that can cause food contamination or spoilage

Personal hygiene - refers to those protection measures primarily with the responsibility of the individual, which promote and limit the spread of infectious disease, like hand washing using soap and water, keep body clean etc.

Risk factor: - a factor whose presence is associated with an increased probability of bacterial hand contamination

\section{Result}

Two hundred thirty food handlers were participated in this study making a response rate of $95.83 \%$. From these $194(84.3 \%)$ of participants were females while $36(7.7 \%)$ were males. The mean and median age of the study subjects were $28.65(\mathrm{SD}=8.09)$, and 26 respectively, whereas the minimum and maximum ages were 18 and 55 years respectively.

About half of the food handlers 119(51.7\%) were single, while $86(37 \%)$ of were married. The educational background is found as no formal education $28(12.2 \%)$, elementary school $115(50 \%)$, secondary school 72(31.3\%), high school and above 15(6.5\%). Regarding their job position 73(31.7\%) were Cookers, 99(41.3\%) were servers and $58(25.2 \%)$ were cleaners. Concerning service years, majority 185 (63\%) of food handlers have served for a period of less than five years in the student cafeterias of JU (Table 1).

\begin{tabular}{|c|c|c|c|}
\hline \multicolumn{2}{|c|}{ Variables categories } & \multirow{2}{*}{$\begin{array}{l}\text { Frequency } \\
36\end{array}$} & \multirow{2}{*}{$\begin{array}{l}\text { Percent (\%) } \\
15.7\end{array}$} \\
\hline Sex & Male & & \\
\hline & Female & 194 & 84.3 \\
\hline \multirow[t]{4}{*}{ Age } & $\leq 20$ years & 33 & 14.4 \\
\hline & $21-30$ years & 124 & 53.9 \\
\hline & $31-40$ years & 47 & 20.4 \\
\hline & 41 & 26 & 11.3 \\
\hline \multirow[t]{3}{*}{ Marital-status } & Single & 119 & 51.7 \\
\hline & Married & 86 & 37.4 \\
\hline & Divorced & 25 & 10.9 \\
\hline \multirow[t]{6}{*}{ Ethnicity } & Oromo & 89 & 38.7 \\
\hline & Amhara & 56 & 24.3 \\
\hline & Gurage & 18 & 7.8 \\
\hline & Dawuro & 32 & 13.9 \\
\hline & Kafa & 16 & 7.0 \\
\hline & Others & 19 & 8.3 \\
\hline \multirow[t]{3}{*}{ Religion } & Orthodox & 118 & 51.3 \\
\hline & Muslim & 60 & 26.1 \\
\hline & Protestant & 52 & 22.6 \\
\hline \multirow[t]{4}{*}{ Education } & Illiterate & 28 & 12.2 \\
\hline & Elementary & 115 & 50.0 \\
\hline & Secondary & 72 & 31.3 \\
\hline & High-school \& above & 15 & 6.5 \\
\hline \multirow[t]{3}{*}{ Job-position } & Cook & 73 & 31.7 \\
\hline & Waiter & 99 & 43.1 \\
\hline & Cleaner & 58 & 25.2 \\
\hline \multirow[t]{5}{*}{ Service years } & $<2$ & 58 & 25.2 \\
\hline & $2-4$ & 87 & 37.8 \\
\hline & $5-7$ & 40 & 17.4 \\
\hline & $8-10$ & 25 & 10.9 \\
\hline & $>10$ & 19 & 8.7 \\
\hline \multirow[t]{2}{*}{ Income } & 420 & 160 & 69.6 \\
\hline & 470 & 70 & 30.4 \\
\hline
\end{tabular}

Table 1: Distribution of socio-demographic characteristics of food handlers working in the student cafeterias of JU main campus, May 2012-Aprill 2013. 
Citation: $\quad$ Assefa T, Tasew H, Wondafrash B, Beker J (2015) Contamination of Bacteria and Associated Factors among Food Handlers Working in the Student Cafeterias of Jimma University Main Campus, Jimma, South West Ethiopia. Altern Integr Med 4: 185.

Page 5 of 8

\section{Personal hygiene practices of food handlers}

In the present study out of the total participants 164 (71.3\%) have worn outer protective Coat, 93(40.4\%) have worn appropriate hair cover, 120 (52.2\%) have kept their outer garments clean. Out of the total participants $160(69.6 \%)$ have got informal food hygiene training, 131(57\%) have got regular medical checkups, $185(80.4 \%)$ have trimmed fingernails, and 58(25.2\%) have worn rings. Out of the total participants hand washing habit using soap and water is reported by $177(77 \%)$ after toilet, 132 (57.4\%) after touching dirty materials, and 201(57\%) before food handling (Table 2).

\begin{tabular}{|c|c|c|c|}
\hline Variables & Categories & Frequency & $\begin{array}{l}\text { Percent } \\
(\%)\end{array}$ \\
\hline \multirow[t]{2}{*}{ Protective outer garment } & Observed & 164 & 71.3 \\
\hline & Not observed & 66 & 28.7 \\
\hline \multirow[t]{2}{*}{ Hair cover } & Observed & 93 & 40.4 \\
\hline & Not observed & 137 & 59.6 \\
\hline \multirow{2}{*}{$\begin{array}{l}\text { Hand washing habit after } \\
\text { toilet }\end{array}$} & With soap and water & 177 & 77.0 \\
\hline & With water only & 53 & 23.0 \\
\hline \multirow{2}{*}{$\begin{array}{l}\text { Hand washing habit after } \\
\text { touching dirty materials }\end{array}$} & With soap and water & 132 & 57.4 \\
\hline & With water only & 98 & 42.6 \\
\hline \multirow{2}{*}{$\begin{array}{l}\text { Hand washing habit } \\
\text { before handling food }\end{array}$} & With soap and water & 201 & 87.4 \\
\hline & With water only & 29 & 12.6 \\
\hline \multirow[t]{2}{*}{ Finger nail status } & Trimmed & 185 & 80.4 \\
\hline & Semi-trimmed & 45 & 19.6 \\
\hline \multirow[t]{2}{*}{ Medical examination } & Checked & 131 & 57.0 \\
\hline & Not checked & 99 & 43.0 \\
\hline \multirow[t]{2}{*}{ Presence of rings } & Observed & 58 & 25.2 \\
\hline & Not observed & 172 & 74.8 \\
\hline \multirow[t]{2}{*}{ Hygiene training } & Trained & 160 & 69.6 \\
\hline & Not trained & 70 & 30.4 \\
\hline
\end{tabular}

Table 2: Personal hygiene practices of food handlers working in the student cafeterias of JU main campus, May 2012 to April 2013.

\section{Types and prevalence of potential food borne bacterial hand contaminants}

Bacteriological investigation of 230 hand rinse samples was performed out of which $114(49.6 \%)$ tested positive for one or more potential food borne bacterial hand contaminants, and 73(31.7\%) were tested positive for Enteric pathogens. A total of 171 bacteria were isolated from which 109 (63.7\%) cases belong to the family of Enterobacteriaceae. In this study the following bacteria's were isolated with the corresponding prevalence rate: Staphylococcus aureus 54(23.5\%), Klebsiella spp. 37(16.1\%), E. coli 25(10.9\%), and Enterobacter spp. 21(9.1\%), Citrobacter spp. 10(4.3\%), Pseudomonas aeruginosa 8(3.5\%), Serratia marcescens 6(2.6\%), Proteus spp. 5(2.2\%), Providencia rettegri $3(1.3 \%)$, and salmonella species $2(0.9 \%)$. While no shigella species was isolated (Table 3 ).

\begin{tabular}{|l|l|l|}
\hline Bacteria isolated & Frequency & Percent (\%) \\
\hline $\begin{array}{l}\text { Staphylococcus } \\
\text { aureus }\end{array}$ & 54 & 23.5 \\
\hline E. coli & 25 & 10.9 \\
\hline Klebsiella spp. & 37 & 16.1 \\
\hline Enterobacter spp. & 21 & 9.1 \\
\hline Citrobacter spp. & 10 & 4.3 \\
\hline Proteus spp. & 5 & 2.2 \\
\hline Serratia marcescens & 6 & 2.6 \\
\hline Providencia rettegri & 3 & 1.3 \\
\hline $\begin{array}{l}\text { Pseudomonas } \\
\text { aeruginosa }\end{array}$ & 8 & 3.5 \\
\hline Salmonella spp. & 2 & 0.9 \\
\hline
\end{tabular}

Table 3: Type and prevalence of potential food borne bacterial hand contaminants among food-handlers working in the student cafeterias of JU main campus, May 2012 to April 2013.

\section{Factors associated with bacterial hand contamination}

In the present study, no statistical association was found between bacterial hand contamination rate, and gender, educational background, job position, medical check-up, food hygiene training, hand washing habit, and fingernail status. However, bacterial hand contamination rate have significant association with service years, age, and cleanness of outer garments.

The isolation rate of potential food borne bacterial hand contaminants was much higher $25(75.8 \%)$ among food-handlers of $\leq 20$ years age group, and lower $10(38.5 \%)$ among those $\geq 41$ years age group. There is significant difference in isolation rate of potential food borne bacterial hand contaminants by age groups (Chi-square $=11.308$, $\mathrm{DF}=3, \mathrm{P}=0.01$ ) (Figure 2).

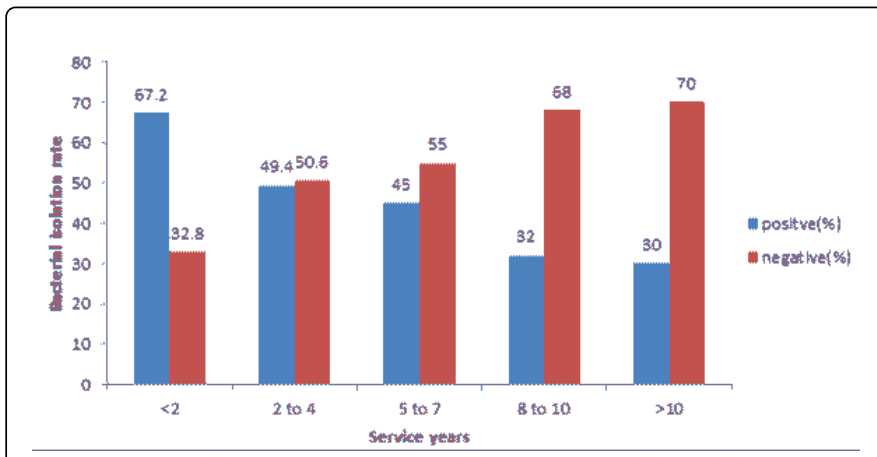

Figure 2: Isolation rate of potential food borne bacterial pathogens among food-handlers working in the student cafeterias of JU main campus in accordance to their service years, May 2012 to April 2013.

Bacterial hand contamination rate have significant association with service years of participants $\left(\chi^{2}=13.732, \mathrm{DF}=4, \mathrm{P}=0.008\right)$. The isolation rate of potential food borne bacterial hand contaminants was relatively 
Citation: Assefa T, Tasew H, Wondafrash B, Beker J (2015) Contamination of Bacteria and Associated Factors among Food Handlers Working in the Student Cafeterias of Jimma University Main Campus, Jimma, South West Ethiopia. Altern Integr Med 4: 185.

Page 6 of 8

higher 39(67.2\%) among food handlers served for a period of less than two years, and lower $6(30 \%)$ among those served for a period of greater than 10 years.

The isolation rate of bacterial hand contaminants was lower 49 (40.8\%) among participants with clean outer garments, compared to $65(59.1 \%)$ with unclean outer garments. There is significant association between bacterial hand contamination rate and cleanness of outer garments $\left(\chi^{2}=7.653, \mathrm{P}=0.006\right)$ (Table 4$)$.

\begin{tabular}{|l|l|l|l|l|}
\hline Gender & \multicolumn{2}{|l|}{ Hand rinse culture result } & Total (\%) & \\
\cline { 2 - 3 } & $\begin{array}{l}\text { Positive } \\
(\%)\end{array}$ & $\begin{array}{l}\text { Negative } \\
(\%)\end{array}$ & \multirow{2}{*}{$\begin{array}{l}\text { X2=0.448, DF=1 } \\
\text { Pvalue= 0.503 }\end{array}$} \\
\hline Female & $98(50.5)$ & $96(49.5)$ & $194(84.3)$ & \\
\hline Male & $16(44.4)$ & $20(55.6)$ & $36(15.7)$ & \\
\hline Total & 114 & 116 & $230(100)$ & \\
\hline
\end{tabular}

Table 4: Bacterial hand contamination rate and associated factors among food handlers working in the student cafeterias of JU main campus, May 2012 to April 2013.

\section{Discussion}

Food handlers are an important vehicle for microorganisms, and improper handling practices may cause food contamination and consequently food borne diseases, which pose a potential risk to public health [31]. This study is taken to assess bacterial hand contamination among food handlers working in the student cafeterias of Jimma University main campus.

In this study $49.6 \%$ participants' hands were contaminated with one or more potentially food borne bacterial contaminants Staphylococcus aureus $23.5 \%$, Klebsiella species $16.1 \%$, E. coli $0.9 \%$, Enterobacter species $9.1 \%$, Citrobacter species $4.3 \%$, are among the most commonly isolated bacterial hand contaminants. The overall hand contamination rate of enteric bacterial contaminants was $31.7 \%$ among the participants. Similar types of bacterial contaminants were identified in Gondar [32], Nigeria [33], Egypt [34], Iran [35], Brazil [36] and Turkey [37].

Toxin-producing strains of Staphylococcus aureus are the leading cause of gastroenteritis following handling of food by persons who carry this bacterium in their noses and skin [38]. The present study Staphylococcus aureus were isolated from $23.5 \%$ food handlers' hands. This figure is comparable to $16.5 \%, 17.5 \%$, and $31 \%$ prevalence reported in Gondar, Saudi Arabia, and Egypt respectively [32,34,39]. However, it is higher than $12.6 \%$, and $7.1 \%$ incidence reported in Iran [31], and Nigeria [29] respectively. Nevertheless, the finding of the current study is lower than $42 \%$, and $70 \%$ prevalence reported in Mexico [40], and Turkey [37] respectively. The discrepancy in socioeconomic status, type of food establishment, and lack of personal hygiene may explain this difference. The Isolation of Staphylococcus aures, reflect improper hygiene practices such as pocking fingers into the nose.

Enteric pathogens that are believed to be capable of being transmitted by food workers include, but are not limited to, E. coli, Salmonella spp., Shigella spp. In addition, pathogens such as Proteus, and Klebsiella, which could originate from raw animal products, can contaminate hands from where they could be transferred to foods, equipment and other workers [15].

Enteric pathogens are among the transient hand flora that can be easily removed by hand washing. Isolation of these organisms includes a faeces-to-hand spread and indicating a poor hygiene practices of the food handlers [41]. Their presence indicates fecal contamination and poor hygiene practices food handlers are not taking enough care of hand hygiene [42]. In the present study' Enterobacteriaceae were identified from hands of $31.7 \%$ food handlers'. This result is nearly comparable to $38 \%$ isolation rate reported in Mexico [40,43], and higher than 6.9\% reported in Egypt [39]. However it is lower than $44 \%$, and 55.6\% reported in South Africa [20], and Brazil [31,34] respectively. This could be resulted due to difference in source population, and type of food establishment. Isolation of Enterobacteriaceae from hands reflects contamination with fecal matter, and inadequate and poor hand washing habit which may pose potential risk of food borne outbreaks.

E. coli is naturally found in the human intestine and although most strains are harmless, some serotypes 0157:H7 can cause serious illness [44]. E. coli is normally absent from hands and the presence of E. coli gives a better indication of recent fecal contamination with enteric pathogens [20]. E. coli was detected on the hands of $10.9 \%$ of food handlers' in the current study, which is in line with $7.8 \%$, and $6.8 \%$ carriage reported in Turkey, and Brazil respectively [36,37]. However, it is lower than $22 \%$ carriage reported in Iran [36]. Nevertheless, this figure is higher than $3.9 \%, 3.1 \%, 2.5 \%$, and $1.8 \%$ isolation rate reported in Turkey [25], Gondar [32], Saudi Arabia [34], and Nigeria [33] respectively. The difference between our results and the previous studies may be attributed to sampling techniques.

In our study, no significant association was found for bacterial hand contamination by sex, educational background, medical check-up, training status, hand washing habit, and fingernail status of food handlers. However, there was significant association between bacterial hand contamination rate and service years (Chi-square $=13.732, \mathrm{DF}=4$, $\mathrm{P}<0.05)$. This result indicated that food handlers more work experience have less risk of bacterial hand contamination. This could be explained as food handlers with more work experience have better personal hygienic practices than inexperienced food handlers. There is a significant difference in bacterial hand contamination rate among different age groups $\left(\chi^{2}=11.308, \mathrm{DFP}=3, \mathrm{P}=0.010\right)$. This can be explained as younger food handlers have poor hygienic practices. The bacterial hand contamination rate has significant association Cleanness of outer garments $\left(\chi^{2}=7.653, \mathrm{DF}=1, \mathrm{P}=0.006\right)$. Undoubtedly, in-depth training about personal hygienic practices of new employees, inexperienced, and young food handlers could minimize the effect of service on bacterial hand contamination rates

Persons working in food services have to go through periodic medical examination. The interview result of our study showed that only $56.7 \%$ of food handlers had taken medical checkup. This figure is comparable to $63.2 \%$ reported in Mekele University [45]. However, it is much higher than $22.7 \%$ reported in Mekele [46], and the result reported in Bahirdar in which none of the participants come across regular medical examinations $[47,48]$. The difference with respect to medical checkup can be explained by better provision and enforcement in Jimma University.

It is known that improper handling is one of the main causes of food borne disease and that inappropriate hand hygiene is an 
Citation: $\quad$ Assefa T, Tasew H, Wondafrash B, Beker J (2015) Contamination of Bacteria and Associated Factors among Food Handlers Working in the Student Cafeterias of Jimma University Main Campus, Jimma, South West Ethiopia. Altern Integr Med 4: 185.

important risk factor for food contamination [31]. Food handlers should always wash their hands when their level of cleanliness may affect food quality; for example: just before food handling, after any interruption, after touching contaminated material, after using the bathroom and whenever else needed. They should not smoke, sneeze, spit, cough, eat, handle money or engage in any act that could contaminate the food during the performance of their activities [23].

Hygienic assessment of the food handlers revealed that $77 \%$ of food handlers have a habit of hand washing with soap and water after toilet, while others used only water. This figure is nearly similar to $70.4 \%$, and $89 \%$ reported in Mekele, and Gondar respectively [32,38]. However, it was lower than $90.6 \%$ a reported in Bahirdar [44]. In the present study only $57 \%$ of food handlers have hand washing habit after touching dirty materials, and different body parts such as nose. This result shows food handlers negligence, and lack of awareness on sources of food contamination.

Food handlers should receive training before starting work in any food establishment, with a periodic refreshing training [47]. In this study $68.7 \%$ food handlers have got short course of training on food hygiene. This figure is much higher than $14 \%$, and $12.3 \%$ reported in Bahirdar, and Mekele respectively [44,48]. This gap can be due to both studies enumerated only certified trainings. However, in the current study food handlers have got only short course of food safety training organized by the student cafeteria office. None of the food handlers were certified by formal training. Effective training of food handlers, may lead to an improvement in hygienic practices.

Food handlers should cover hair and wear appropriate protective covering, cut their fingernails short and during handling they should remove jewelry from their hands[47]. In the present study, 164 $(71.3 \%)$ food handlers were observed wearing outer working Coat, while only $40.4 \%$ had worn hair net. This result is in line with the report a cross-sectional study in mekele in which $72.6 \%$ of the food handlers were found wearing outer working garments, and $39 \%$ had worn hair net [38]. Nevertheless, it is higher than the figure reported in Ambo in which only $28 \%$ of food handlers' worn outer garment and hair covers [48]. This gap might be due to differences in socioeconomic condition.

Moreover, in our study $80.4 \%$ of food handlers' fingernails were trimmed. This figure is by far comparable to $76.2 \%$, and $88.4 \%$ reported in Mekele town [42], and Mekele University [44] respectively. However, it is higher than 70\% reported in Ambo [49]. Even though it had no association with the isolation rate of potential bacterial pathogens in this study, fingernails can serve as a vehicle for transport of microorganisms from their source to the foods or/and directly into the body. Beside this, $25.2 \%$ food handlers have worn finger ornaments. This figure is similar to $27.1 \%$ reported in Ambo [28], and lower than 35.7\% reported in Mekele [38].

\section{Limitation of the Study}

As far as the study design is cross sectional, it simply provides information about relationship between the dependent and independent variables. Beside this Total Plate Count and Colliform count were not done because of resource and time constraint. Serological identification of Salmonella species was not carried out. Antimicrobial susceptibility test for potential food borne bacterial contaminants was not done. Moreover, there is a scarcity of studies focused on isolation of bacteria from hands. This fact makes difficult the comparison of our results with that found by other researchers especially from developing countries.

\section{Conclusion and Recommendations}

In conclusion, our findings showed 114 (49.6\%) carriage of potential food borne bacterial hand contaminants and 73(31.7\%) were tested positive for enteric bacterial hand contaminants. The following food borne bacterial hand contaminants were isolated with the corresponding prevalence rate: S. aureus 54(23.5\%), Klebsiella spp. 37(16.1\%), E. coli 25(10.9\%), Enterobacter spp. 21(9.1\%), Citrobacter spp. 10(4.3\%), Serratia marcescens 6 (2.6\%), Pseudomonas aeruginosa 8(3.5\%), Proteus spp. 5(2.2\%), Providencia rettegri 3(1.3), and salmonella spp. $2(0.9 \%)$. These findings emphasized the importance of food handlers hand as potential vector of food borne bacterial pathogens that could constitute a potential risk of food borne disease outbreaks. Bacterial hand contamination rate have significant association with service years (Chi-square $=13.732, \mathrm{DF}=4, \mathrm{P}=0.008$ ), age $\left(\chi^{2}=11.308, P=0.010\right)$ and cleanness of outer garments $\left(\chi^{2}=7.653\right.$, $\mathrm{P}=0.006$ ). Despite short course of informal food hygiene training none of the participants has been certified by formal training.

Based on the findings of the study the following recommendations are made:

\section{As a responsible body to Jimma University:}

Instruction regarding proper methods of hand washing should become a part of new employees, as well as young and inexperienced food handlers' orientation, education.

Food handlers should be well trained about personal hygienic practices pointing out on importance of hand hygiene and cleanness of outer garments

Close follow up, and regular supervision of personal hygienic practices of food handlers should be used as controlling strategies

Future studies should focus on enumeration of bacterial hand contaminants, and assessing sanitary facilities of the working environment.

\section{References}

1. WHO (2002) WHO global strategy for food safety: safer food for better health. Geneva, Switzerland.

2. http://www.afro.who.int/index.php?option=com_docman\&task=doc.

3. WHO Consultation (2006) World Health Organization (WHO) Consultation to Develop a Strategy to Estimate the Global Burden of Food borne Diseases.

4. Centers for Disease control and Prevention (2005) Foodborne Illness. International Food Safety Consultancy.

5. World Health Organization (2007) Food Safety and Foodborne IllnessFact sheet No. 237.

6. Centers for Disease control and Prevention (CDC) (2005) Foodborne Illness. International Food Safety Consultancy.

7. CDC (2011) Estimates. CDC Estimates of Foodborne Illness in the United States. National Center for Emerging \& Zoonotic Infectious Diseases Division of Foodborne, Waterborne, and Environmental Diseases.

8. World Health Organization (2000) Food borne Disease: A focus for Health Education. Geneva.

9. FAO Food and Nutrition (2003) Joint FAO/WHO Publication Assuring Food Safety and Quality: Guidelines For Strengthening National Food Control Systems. Paper 76. 
Citation: $\quad$ Assefa T, Tasew H, Wondafrash B, Beker J (2015) Contamination of Bacteria and Associated Factors among Food Handlers Working in the Student Cafeterias of Jimma University Main Campus, Jimma, South West Ethiopia. Altern Integr Med 4: 185.

10. Brundtland GH. Food Chain 2001 - "Food Safety a World-wide Challenge. WHO, Uppsala, Sweden, updated.

11. Ministry of Health (2011) Planning and Programming Department. Health and Health Related Indicators.

12. WHO (2004) World Health Organization global strategy for food safety: safer food for better health.

13. Käferstein FK (2003) Food safety: the fourth pillar in the strategy to prevent infant diarrhoea Bull World Health Organ 81: 842-843.

14. Zain MM, Naing NN (2002) Sociodemographic characteristics of food handlers and their knowledge, attitude and practice towards food sanitation: a preliminary report. Southeast Asian J Trop Med Public Health 33: 410-417.

15. Michaels B, Keller C, Blevins M, Paoli G (2004) Prevention of food worker transmission of foodborne pathogens: risk assessment and evaluation of effective hygiene intervention strategies. Food Service Technology.

16. Guzevich J, Ross M (1999) Evaluation of risks related to microbiological contamination of ready-to-eat food by food preparation workers and the effectiveness of interventions to minimize those risks.

17. Gun W, Satu S (2007) Microbial contaminants \& Contamination routes in food industry: 1st open seminar arranged by SAFOODNET in food safety and hygiene networking within new member states and associated candidate Countries.

18. Mohan V (2001) An evaluation of health status of food handlers of eating establishments in various educational and health institutions in Amritsar City. Indian Journal of Community Medicine 26(2): 80-84.

19. Bloomfield SF, Nath KJ (2009) Use of ash and mud for hand washing in low income communities. An IFH expert review.

20. Pickering AJ, Boehm AB, Mwanjali M, Davis J (2010) Efficacy of waterless hand hygiene compared with handwashing with soap: a field study in Dar es Salaam, Tanzania. Am J Trop Med Hyg 82: 270-278.

21. Murat B, Azmi SE, Gokhan K (2006) The evaluation of food hygiene knowledge, attitude, and practice of food handlers in food businesses in Turkey. Food Control 17: 317-322.

22. Lues JFR, Tonder IV (2007) The occurrence of indicator bacteria on hands and aprons of food handlers in the delicatessen sections of a retail group. Food Control 18(4): 326-332.

23. Snyder OP (2010) A "Safe Hands" Hand wash program for retail food operations. Hospitality Institute of Technology and Management.

24. Codex Alimentarius (2003) Recommended international code of practice general principles of food hygiene. CAC/RCP 1-1969.

25. Harrison WA, Griffith CJ, Ayers T, Michaels B (2003) Bacterial transfer and cross-contamination potential associated with paper-towel dispensing. Am J Infect Control 31: 387-391.

26. Acikel CH, Ogur R, Yaren H, Gocgeldi E (2008) The hygiene training of food handlers at a Teaching Hospital. Food Control.

27. Fagernes M, Lingaas E (2011) Factors interfering with the microflora on hands: a regression analysis of samples from 465 healthcare workers. J Adv Nurs 67: 297-307.

28. Josie L, Traub-Dargatz, J, Weese S, Rousseau JD (2006) Pilot study to evaluate 3 hygiene protocols on the reduction of bacterial load on the hands of veterinary staff performing routine equine physical examinations. Can Vet J 47: 671-676.

29. Cheesbrough M (2003) Medical Laboratory Technology Manual of Tropical Health. Low Priced Edition.Doddington, Cambridgeshire, England, pp146-215.

30. Buchanan RE and Gribbon NE (1974) Bergeys Manual of Determinative Bacteriology. 8th ed. Williams and Wilkins Co; Baltimore, U.S.

31. Campos AKC, Cardonha AMS, Pinheiro LBG, Ferreira NR, et al. (2009) Assessment of personal hygiene and practices of food handlers in municipal public schools of Natal, Brazil. Food Control 20(9): 807-810.
32. Andargie G, Kassu A, Moges F, Tiruneh M, Huruy K (2008) Prevalence of bacteria and intestinal parasites among food-handlers in Gondar town, northwest Ethiopia. J Health Popul Nutr 26: 451-455.

33. Ifeadike CO, Ironkwe OC, Adogu PO, Nnebue CC, Emelumadu OF, et al. (2012) Prevalence and pattern of bacteria and intestinal parasites among food handlers in the Federal Capital Territory of Nigeria. Niger Med J 53: 166-171.

34. Fawzi M, Gomaa NF, Bakr WM (2009) Assessment of hand washing facilities, personal hygiene and the bacteriological quality of hand washes in some grocery and dairy shops in alexandria, egypt. J Egypt Public Health Assoc 84: 71-93.

35. Shojaei H, Shooshtaripoor J, Amiri M (2006) Efficacy of simple handwashing in reduction of microbial hand contamination of Iranian food handlers. Food Research International 39(5): 525-529.

36. Souza PA, Santos DA (2009) Microbiological risk factors associated with food handlers in elementary schools from Brazil. Journal of Food Safety 29(3): 42 .

37. Aycicek H, Aydogan H, Kucukkaraaslan A, Baysallar M, et al. (2004) Assessment of the bacterial contamination on hands of hospital food handlers. Food Control 15(4): 253-259.

38. Do Carmo LS, Cummings C, Linardi VR, Dias RS, De Souza JM, et al. (2004) A case study of a massive staphylococcal food poisoning incident. Foodborne Pathog Dis 1: 241-246.

39. Zaglool DA, Khodari YA, Othman RA, Farooq MU (2011) Prevalence of intestinal parasites and bacteria among food handlers in a tertiary care hospital. Niger Med J 52: 266-270.

40. Dharod JM, Stefania Paciello S, BermÃodez-Millã $\tilde{i n}_{\text {A, }}$ Venkitanarayanan K, et al. (2009); Bacterial Contamination of Hands Increases Risk of Crosscontamination among Low-income Puerto Rican Meal Preparers. J Nutr Educ Behav 41(6): 389-397.

41. Jumaa PA (2005) Hand hygiene: simple and complex. Int J Infect Dis 9: 3-14.

42. Zeru K, Kumie A (2007) The sanitary conditions of food establishments in Mekelle Town, Tigray, North Ethiopia. Ethiop. J Health Dev 21(1): 3-11.

43. Abhay BM, Navetta kA, Gargi AM, Ramachandrah CG (2010) Health status and personal hygiene among food handlers working in food establishments around a rural teaching hospital in Wardah district of Maharashtra, India. Global Journal of Health Science 2(2): 198-207.

44. Taulo S, Wetlesen A, Abrahamsen RK, Narvhus JA, et al. (2009) Quantification and variability of Escherichia coli and Staphylococcus aureus cross-contamination during serving and consumption of cooked thick porridge in Lungwena rural households, Malawi. Food Control 20: 1158-1166.

45. Nigusse D and Kumie A (2012) Food hygiene practices and prevalence of intestinal parasites among food handlers working in Mekelle University students cafeteria, Mekelle. GARJSS 1(4): 065-071.

46. Abera B, Biadegelgen F, Bezabih B. (2010) Prevalence of Salmonella typhi and intestinal parasites among food handlers in Bahir Dar Town, Northwest Ethiopia. Ethiop J Health Dev. 24: 46-50.

47. http://www.afro.who.int/index.php?option=com_docman\&task=doc.

48. Gudeta D (2007) Sanitary Survey of Food and Drinking Establishments in Ambo Town West Showa Zone Oromia Region. MSc. Thesis, Addis Ababa University, Faculty of Medicine.

49. Fadel HM, Ismail J (2009) Prevalence and Significance of Staphylococcus aureus and Enterohacteriaceae species in Selected Dairy Products and Handlers. International Journal of Dairy Science 4 (3): 100-108. 